\title{
Implementing Instructional Supervision by an Operating Room Assistant to Reduce Turnover Time 纙
}

\author{
Xiaohua Pan ${ }^{1}$, Hui Zhou ${ }^{1}$, Weihua $\mathrm{Li}^{1}$, Jie Zhang ${ }^{2}$, Yibing $\mathrm{Si}^{3}$ and Gendi Li ${ }^{4 *}$ \\ ${ }^{1}$ Department of Operation Room, Huashan Hospital North, Fudan University, China \\ ${ }^{2}$ Department of Anesthesiology, Huashan Hospital North, Fudan University, China \\ ${ }^{3}$ Department of Nursing, Huashan Hospital North, Fudan University, China
}

${ }^{4}$ Department of Operation Room, Huashan Hospital, Fudan University, China

Received: April 17, 2018; Published: May 04, 2018

*Corresponding author: Gendi Li, Huashan Hospital, Fudan University, 12 Middle Urumqi Road, Shanghai 200040, China

Abstract

Background: Turnover time is still not negligible in ensuring efficient operating room(OR) management. A prospective study was performed to evaluate the effect of instructional supervision by an OR assistant on reducing turnover time.

Material and Methods: We prospectively included surgical cases undergoing turnover operation after the first case from two ORs in a single center between Mar 2015 and Feb 2016. Cases in one OR received the instructional supervision by an OR assistant. Cases in another OR received not. The primary endpoint was the percentage of surgical case with turnover time $\leq 45 \mathrm{~min}$. Other endpoints were turnover time, the percentage of the teamwork score of OR staffs $\geq 4$ point and the percentage of patient satisfaction score $\geq 4$ point.

Results: Over 48 weeks, the effect of instructional supervision was evaluated in 1826 surgical cases undergoing turnover operation. Compared with those in the non-intervention group(n=904), the percentage of surgical cases with turnover time $\leq 45 \mathrm{~min}$ decreased significantly $(80.4 \%$ VS $59.6 \%, \mathrm{P}<0.001)$ in the instructional supervision group(n=922). In the instructional supervision group, there was a significant improvement in turnover time $(49.6 \mathrm{~min}$ VS $37.9 \mathrm{~min} ; \mathrm{P}<0.001)$, the percentage of the teamwork score $\geq 4$ point $(84.8 \%$ VS $79.4 \%$; $\mathrm{P}=0.003)$ and the percentage of patient satisfaction score $\geq 4$ point $(89.7 \%$ VS $78.1 \%, \mathrm{P}<0.001)$.

Conclusion: Implementing instructional supervision by an OR assistant can potentially reduce our OR turnover time.

Keywords: Operating Room; Turnover Time; Instructional Supervision

Abbreviations: OR: Operating Room; Team STEPPS: Team Strategies and Tools to Enhance Performance and Patient Safety

\section{Introduction}

Hospitals must focus on improving operating room(OR) efficiency to achieve an appropriate target of high-quality, lowcost care. Eight efficiency indicators including time management were identified as most critical for monitoring OR performance [1]. Improving intraoperative efficiency-time savings may translate to an earlier finish or the opportunity to perform more cases during the same block time [2]. A surgeon's operative time can be difficult to regulate as each procedure can have different degrees of difficulty due to patient-specific factors. However, many of the processes in the OR are common, particularly those not associated with the procedure itself, and these might be optimized to assure more efficient and better care such as turnover time [3]. In China, there are a huge amount of operations in every large size tertiary comprehensive hospital, it is urgent to reduce turnover time for minimum economic costs.In previous two before-after controlled studies [4,5] lean Six Sigma methodology and another changed lean methodology were applied to decrease OR turnover time. But these broadly applicable interventions based on strategies used in other time pressured industries and translated into health care, can provide the basis for considerable and sustainable improvements in turnover time. Weld LR et al. [6] found Team STEPPS (team strategies and tools to enhance performance and patient safety) had no effects on OR turnover time. There have been no prospective parallel-controlled studies to specifically evaluate the effect of instructional supervision on OR turnover time.Long, inefficient and unpredictable OR turnover time can reduce surgical productivity, affecting the ability to treat patients, with potentially serious financial implications [7]. The aim of this study is to assess whether 
an intervention implementing instructional supervision by an OR assistant would impact OR turnover time.

\section{Subjects and Methods}

A prospective parallel-controlled study was designed at Huashan Hospital North, Fudan University. Data were from the surgical cases performed at two ORs between Mar 2015 and Feb 2016 (48 complete weeks). Cases in one OR received the instructional supervision by an assigned OR assistant. Cases from another OR received not. The modified instructional supervision included timing plan of next case before the final skin closure, communication of necessary anesthetics doses at the time of the final skin closure, prompt patient identification and review before the departure, assisting with patient transfer on and off the bed, helping with the set-up and dissembling of equipment [8]. Cases who had undergone turnover operation after the first case were included in this study. Analysis was limited to cases performed on scheduled workdays. Weekends and the weeks including holidays were excluded. To obtain the standardized data, a definition of turnover time was defined.

Turnover time was defined as the time from first patient exiting to second patient entering the $\mathrm{OR}$ and was obtained from the electronic medical record for those observed cases. It was regulated that turnover time needed to no more than $45 \mathrm{~min}$. If any case did not meet this time standard, it was considered a delayed turnover case. We calculate the percentage of cases with turnover time $\leq 45 \mathrm{~min}$ quarterly. The primary endpoint was the percentage of surgical case with turnover time $\leq 45 \mathrm{~min}$ over 48 weeks. Other endpoints were turnover time, the percentage of the teamwork score of OR staffs $\geq 4$ point and the percentage of patient satisfaction score $\geq 4$ point. The criteria of teamwork score or patient satisfaction score: Score
5 indicating extremely smooth or satisfied; Score 4 indicating quite a bit smooth or satisfied; Score 3 indicating moderately smooth or satisfied; Score 2 indicating a little bit smooth or satisfied; Score 1 indicating not at all smooth or satisfied. The team work score was obtained from OR nurses. Statistical analysis was performed using non-parametric Mann-Whitney U test, Pearson Chi-square test and $\mathrm{T}$ test to compare between groups. Average data presented as standard mean and standard deviation. $\mathrm{P}$ values $<0.05$ were considered statistically significant.

\section{Results}

Table 1: The characteristics of surgical cases undergoing turnover operation after the first case in two observational groups.

\begin{tabular}{|c|c|c|c|}
\hline Characteristics & $\begin{array}{c}\text { Non-Interven- } \\
\text { tion }\end{array}$ & Intervention & P Value \\
\hline \multicolumn{4}{|c|}{ Discipline, $\mathrm{n}(\%)$} \\
\hline General surgery & $385(42.6)$ & $427(46.3)$ & \multirow{2}{*}{0.266} \\
\hline Orthopedic surgery & $406(44.9)$ & $391(42.4)$ & \\
\hline Others & $113(12.5)$ & $104(11.3)$ & \\
\hline \multicolumn{5}{|c|}{ Anesthesia, $\mathrm{n}(\%)$} \\
\hline General anesthesia & $612(67.7)$ & $660(71.6)$ & \multirow{2}{*}{0.184} \\
\hline Lumbar anesthesia & $184(20.4)$ & $169(18.3)$ & \\
\hline Others & $108(11.9)$ & $93(10.1)$ & \\
\hline \multicolumn{5}{|c|}{ Body position, $\mathrm{n}(\%)$} \\
\hline Supine position & $544(60.2)$ & $597(64.8)$ & \multirow{2}{*}{0.113} \\
\hline Lateral position & $231(25.5)$ & $215(23.3)$ & \\
\hline Others & $129(14.3)$ & $110(11.9)$ & \\
\hline
\end{tabular}

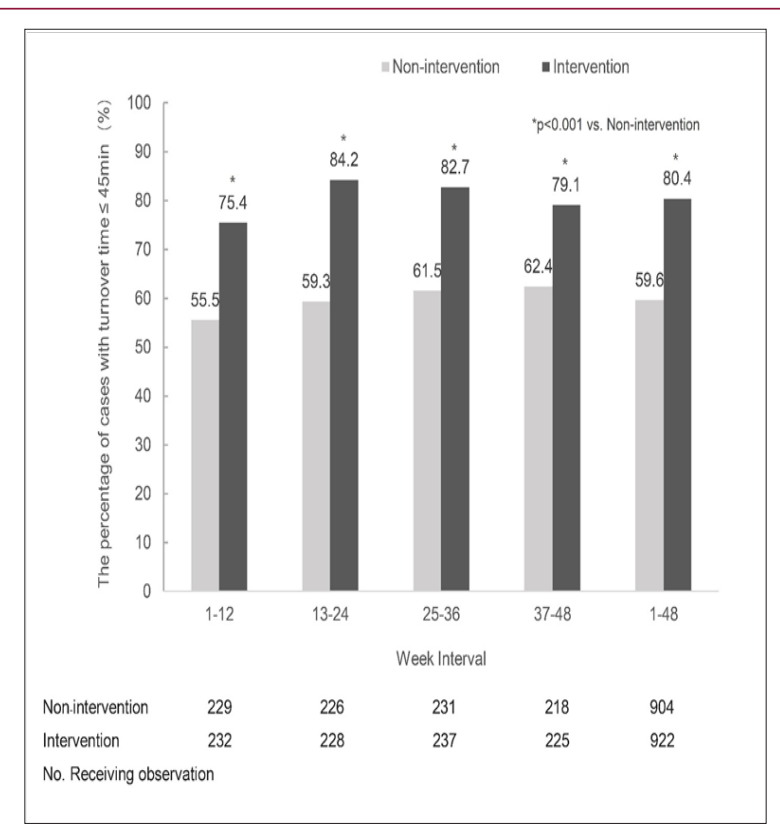

Figure 1: The percentage of cases with turnover time $\leq 45 \mathrm{~min}$ in the instructional supervision group and in the non-intervention group. Data were over every 12 weeks (weeks 1-12, weeks 13-24, weeks 25-36, weeks 37-48, or weeks 1-48). *p<0.001 vs. Nonintervention group. 
Over 48 weeks, the impact of instructional supervision on turnover time was evaluated in 1826 surgical cases undergoing turnover operation. 922 cases received the instructional supervision by an assigned OR assistant in one OR. 904 Cases in another OR received not. The characteristics of these cases was showed in Table 1. They were well matched and were not significantly different between the two tentative groups.During the 48-week observational phase, the percentage of cases with turnover time $\leq 45 \mathrm{~min}$ in the instructional supervision group is significantly higher than that in the non-intervention group per quarter $(p<0.001)$. Continued measurements of the percentage during this study showed the improvement was maintained at least up to 48 weeks of the instructional supervision. These percentage were $80.4 \%$ for the instructional supervision and $59.6 \%$ for the non-intervention over 48 weeks, representing an improvement of $20.8 \%$ with the instructional supervision over the non-intervention $(\mathrm{p}<0.001)$ (Figure 1).

Compared with that in the non-intervention group, there was a shorter turnover time in the instructional supervision group (49.6min VS $37.9 \mathrm{~min}, \mathrm{p}<0.001$ ). The proportion of the teamwork score of OR staffs $\geq 4$ point was significantly greater $(84.8 \%$ VS $79.4 \%$; $\mathrm{P}=0.003$ ) in the instructional supervision group than that in non-intervention group over 48weeks. For cases which received instructional supervision by an assigned OR assistant, a similar improvement of satisfaction was observed over 48 weeks. Evaluating satisfaction by the percentage of patient satisfaction score $\geq 4$ point gives different proportion of satisfied patients $(89.7 \%$ VS $78.1 \%$, $\mathrm{P}<0.001$ ) in two groups Table 2.

Table 2: Comparison of the variable between cases without Intervention and those with intervention of the instructional supervision over 48 weeks.

\begin{tabular}{|c|c|c|c|}
\hline \multirow{2}{*}{ Variable } & $\begin{array}{c}\text { Non- } \\
\text { intervention }\end{array}$ & Intervention & \multirow{2}{*}{ P value } \\
\cline { 2 - 3 } & $\mathbf{n = 9 0 4}$ & $\mathbf{n = 9 2 2}$ & \\
\hline $\begin{array}{c}\text { Turnover time (min, mean } \\
\pm \text { SD) }\end{array}$ & $49.6 \pm 14.2$ & $37.9 \pm 12.5$ & 0.0000 \\
\hline \multicolumn{3}{|c|}{ Staff teamwork, $\mathrm{n}(\%)$} \\
\hline Score $\geq 4$ point & $718(79.4)$ & $782(84.8)$ & 0.003 \\
\hline Score $<4$ point & $186(20.6)$ & $140(15.2)$ & \\
\hline \multicolumn{4}{|c|}{ Patient satisfaction, $\mathrm{n}(\%)$} \\
\hline Score $\geq 4$ point & $706(78.1)$ & $827(89.7)$ & 0.0000 \\
\hline Score $<4$ point & $198(21.9)$ & $95(10.3)$ & \\
\hline
\end{tabular}

\section{Discussion}

ORs are probably among the most important areas of the hospital, contributing to both the workload and the revenue. With the increasing of surgical cases, inefficient OR management can result in long patient waiting lists. Many factors affected the turnover time including an inefficient central processing of instruments or a multidisciplinary problem involving nursing, anesthesia, housekeeping and the turnover team staff not working in co-ordination [9]. Active management of surgical team turnover may be an opportunity to improve operating room efficiency [10]. In our study, an instructional supervision program by an operating room assistant was conducted to significantly reduce turnover time. An earlier study [11] showed that an interprofessional approach by an OR Governance Committee had not affected the turnover time remaining constant at 43 to 44 minutes. But time from patient in room to procedure starting and time from procedure ending to out of room have decreased with an average savings of 8 minutes per case.Such an approach only achieved by consensus maybe common in the aerospace industry but has not been used yet in the OR. Only teamwork cannot achieve an improvement in turnover time. Optimized instructional supervision program by an operating room assistant in our study led to a significant reduction in it. Collaboration with other units, timing and sequencing of patient preparation as well as post-operative care, is therefore important.

Patient leaving and arriving late are the common reasons of delays in OR turnover. Communication to OR team members, patient transfer to stretcher/bed, disconnect anesthesia connections, destination ready and hand-off report were involved in the departure. Patient arriving included communication to OR team members, preparation complete (count), patient transported to OR, patient transferred to bed, hand-off report [12]. Wong J et al. [13] found that the most common cause of delay in OR was equipment failure. In our instructional supervision program, planning preparation of patient leaving and arriving, assisting with patient transfer on and off the bed and the set-up and dissembling of equipment were applied. The delay of turnover was significantly improved. The process of receiving patients and the discharge to ward must be carefully planned to avoid 'bottle necks.'A previous study [14] has demonstrated the impact of anesthesia skills on OR timing. Meanwhile, Leadership skills, good communication and briefing have been shown a positive effect on theatre efficiency [15]. In our instructional supervision program, communication of the plan for next case before the final skin closure and necessary anesthetic doses at the time of the final skin closure were involved. It could influence the turnover time.

A study from Australia reported an average theatre changeover time of around 28min before an intervention [8] and another study for USA showed the baseline of turnover time averaging 53min [16]. In our study, average OR turnover time was $49.6 \mathrm{~min}$ without an intervention and $37.9 \mathrm{~min}$ after 12 months' intervention. The definition turnover time under debate could lead to the results. Usually, turnover time is defined as the time taken between one patient leaving the room and the next entering. Our turnover time was further defined from the electronic medical record for those observed cases.Teamwork score and patient satisfaction are two critical self-assessment indicators which appear to be the problems behind effectiveness in OR. Growing evidence showed the importance of teamwork [17] and patient satisfaction [18] in OR. Patients' willingness to recommend is a very direct and strong indicator of satisfaction. Our program has resulted in patient satisfaction improvements and the enhancement of the OR staff team communication and cooperation.There are several limitations that could influence conclusions drawn from this study. We have also likely not captured all the innovative intraoperative workflow 
solutions that have been introduced and tested. There may be other potentially important factors for bias such as the level of experience of OR team members, new surgical techniques and so on. Results from a single-center experience is another limitation. However, we have no reason to believe that a similar strategy would not be effective at other hospitals.

\section{Conclusion}

Approaches to improving OR turnover time can occur on many levels based on the required level of resources and institutional support. The results highlight the importance of exploring the impact of human factors on surgical team dynamics as part of quality-improvement strategies. The success of implementing instructional supervision by an OR assistant could led to the improvement in OR turnover time.

\section{Acknowledgment}

The authors would like to thank nurses and anesthetists in the operating room of Huashan Hospital North, Fudan University for their involvement and support.

\section{References}

1. Fixler T, Wright JG (2013) Identification and use of operating room efficiency indicators: the problem of definition. Can J Surg 56(4): 224226.

2. Fong AJ, Smith M, Langerman A (2016) Efficiency improvement in the operating room. J Surg Res 204(2): 371-383.

3. Madni TD, Imran JB, Clark A (2017) Analysis of Operating Room Efficiency in a Burn Center. J Burn Care Res.

4. Tagge EP, Thirumoorthi AS, Lenart J (2017) Improving operating room efficiency in academic children's hospital using Lean Six Sigma methodology. J Pediatr Surg 52(6): 1040-1044.

5. Hassanain M, Zamakhshary M, Farhat G, Al-Badr A (2017) Use of Lean methodology to improve operating room efficiency in hospitals across the Kingdom of Saudi Arabia. Int J Health Plann Manag 32(2): 133-146.
6. Weld LR, Stringer MT, Ebertowski JS (2016) Team STEPPS Improves Operating Room Efficiency and Patient Safety. Am J Med Qual 31(5): 408-414.

7. Stahl JE, Sandberg WS, Daily B (2006) Reorganizing patient care and workflow in the operating room: a cost-effectiveness study. Surgery 139(6): 717-728.

8. Soliman BA, Stanton R, Sowter S (2013) Improving operating theatre efficiency: an intervention to significantly reduce changeover time. ANZ J Surg 83(7-8): 545-548.

9. Divatia JV, Ranganathan P (2015) Can we improve operating room efficiency? J Postgrad Med 61(1): 1-2.

10. Azzi AJ, Shah K, Seely A (2016) Surgical team turnover and operative time: An evaluation of operating room efficiency during pulmonary resection. J Thorac Cardiovasc Surg 151: 1391-1395.

11. Bender JS, Nicolescu TO, Hollingsworth SB (2015) Improving operating room efficiency via an interprofessional approach. Am J Surg 209(3): 447-450.

12. Fairbanks CB (2007) Using Six Sigma and Lean methodologies to improve OR throughput. AORN J 86(1): 73-82.

13. Wong J, Khu KJ, Kaderali Z, Bernstein M (2010) Delays in the operating room: signs of an imperfect system. Can J Surg 53(3): 189-195.

14. Browne W, Siu LW, Monagle JP (2011) The impact of anaesthetic trainees on elective caesarean section procedural times: a prospective observational study. Anaesth Intensive Care 39(5): 936-940.

15. Bethune R, Sasirekha G, Sahu A, et al. (2011) Use of briefings and debriefings as a tool in improving team work, efficiency, and communication in the operating theatre. Postgrad Med J 87(1027): 331-334.

16. McDowell J, Wu A, Ehrenfeld JM, Urman RD (2017) Effect of the Implementation of a New Electronic Health Record System on Surgical Case Turnover Time. J Med Syst 41(3): 42.

17. Catchpole K, Mishra A, Handa A, McCulloch P (2008) Teamwork and error in the operating room: analysis of skills and roles. Ann Surg 247(4): 699-706.

18. Saver C (2014) Patient safety, satisfaction rise to top of priority list. OR Manager 30: 11-13.

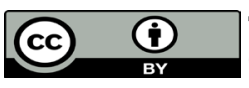

This work is licensed under Creative Commons Attribution 4.0 License

Submission Link: https://biomedres.us/submit-manuscript.php

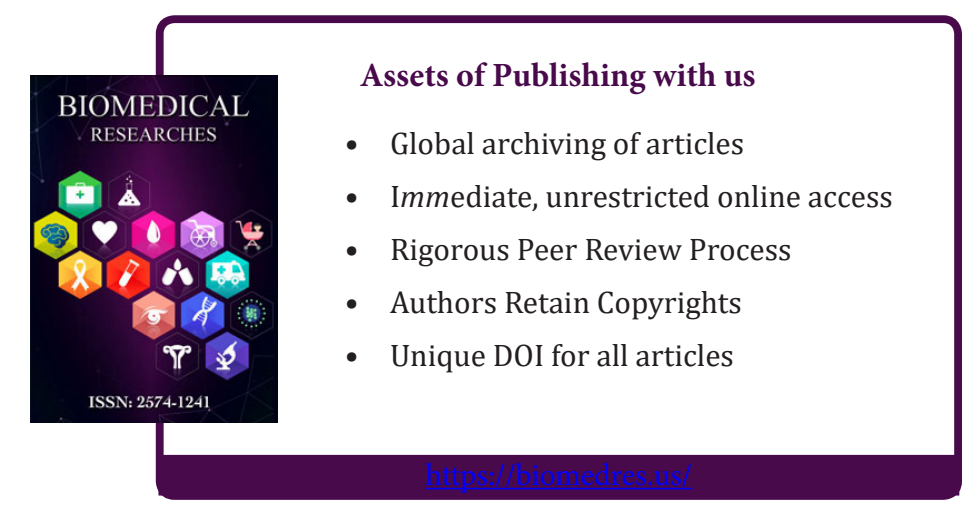

